\title{
Erratum to: Serum chitotriosidase in postmenopausal women with severe osteoporosis
}

\author{
M. Musumeci ${ }^{1,3}$ - A. Palermo ${ }^{2}$ L. D'Onofrio ${ }^{2}$ - G. Vadalà $^{3}$ - V. Greto ${ }^{2}$ E. Di Stasio ${ }^{4}$.

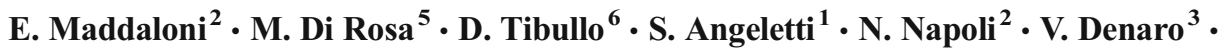 \\ S. Manfrini ${ }^{2}$
}

Published online: 19 January 2016

(C) International Osteoporosis Foundation and National Osteoporosis Foundation 2016

\section{Erratum to: Osteoporos Int}

\section{Doi 10.1007/s00198-015-3254-3}

The given name and family name of the tenth author were transposed in the manuscript accepted for publication and were thus incorrect in the article. Her name is S. Angeletti (not A. Silvia).

The online version of the original article can be found at http://dx.doi.org/ 10.1007/s00198-015-3254-3.

A. Palermo

a.palermo@unicampus.it

1 Clinical Pathology and Microbiology Laboratory, University Campus Bio-Medico, Rome, Italy

2 Department of Endocrinology and Diabetes, University Campus Bio-Medico, Via Alvaro del Portillo, 21-00128 Rome, Italy

3 Department of Orthopaedic Surgery, University Campus Bio-Medico, Rome, Italy

4 Institute of Biochemistry and Clinical Biochemistry, University Cattolica del Sacro Cuore, Rome, Italy

5 Department of Bio-medical Sciences, University of Catania, Catania, Italy

6 Department of Clinical and Molecular Biomedicine, University of Catania, Ospedale Ferrarotto, Catania, Italy 